\title{
Effect of Wnt1 and Wnt5a on the development of dopaminergic neurons, and toxicity induced by combined exposure to paraquat and maneb during gestation and lactation
}

\author{
JING MA ${ }^{1}$, CUI HUANG ${ }^{1,2}$, KUN MA $^{1}$, YAN-PING WU ${ }^{1}$, BAI-XIANG LI $^{1 *}$ and YAN SUN ${ }^{*}$ \\ ${ }^{1}$ Department of Toxicology, School of Public Health, Harbin Medical University, Harbin, Heilongjiang 150081; \\ ${ }^{2}$ Wuchang Rice Research Institute, Heilongjiang Academy of Agricultural Sciences, Harbin, Heilongjiang 150229, P.R. China
}

Received February 21, 2017; Accepted September 13, 2017

DOI: $10.3892 / \mathrm{mmr} .2017 .7833$

\begin{abstract}
Paraquat (PQ) and maneb (MB) are widely used herbicides. Wingless (Wnt) proteins serve a role in the development and differentiation of dopaminergic neurons. Previous studies demonstrated that combined exposure to $\mathrm{PQ}$ and $\mathrm{MB}$ damages dopaminergic neurons in the midbrain. Effects of PQ and MB exposure on midbrain Wnt proteins have also been previously reported. In the present study, from the 5th day of gestation to weaning of the offspring, pregnant Sprague-Dawley rats were administrated saline, or PQ and $\mathrm{MB}$ at two different doses: high, $15 \mathrm{mg} / \mathrm{kg}$ body weight $\mathrm{PQ}+45 \mathrm{mg} / \mathrm{kg}$ body weight $\mathrm{MB}$; or low, $10 \mathrm{mg} / \mathrm{kg}$ body weight $\mathrm{PQ}+30 \mathrm{mg} / \mathrm{kg}$ body weight MB. Dopamine content in the striatum was examined by high performance liquid chromatography with a fluorescence detector and mRNA and protein expression of Wnt1, Wnt5a, nuclear receptor related factor 1 (Nurr1) and tyrosine hydroxylase (TH) in the midbrain was examined by reverse transcription-quantitative polymerase chain reaction and western blotting. Combined exposure to PQ and MB during development decreased mRNA and protein expression of Wnt1, TH and Nurrl and increased expression of Wnt5a in the offspring.
\end{abstract}

Correspondence to: Professor Bai-Xiang Li or Professor Yan Sun, Department of Toxicology, School of Public Health, Harbin Medical University, 157 Baojian Road, Harbin, Heilongjiang 150081, P.R. China

E-mail: libaix@ems.hrbmu.edu.cn

E-mail: 13946167049@163.com

${ }^{*}$ Contributed equally

Abbreviations: $\mathrm{PQ}$, paraquat; $\mathrm{MB}$, maneb; $\mathrm{TH}$, tyrosine hydroxylase; Wnt1, wingless 1; Wnt5a, wingless 5a; PD, Parkinson's disease; HPLC-FL, high performance liquid chromatography with a fluorescence detector; DA, dopamine; Nurr1, nuclear receptor related factor 1; $\mathrm{MPP}^{+}$, 1-methyl-4-phenylpyridinium

Key words: Parkinson's disease, paraquat, maneb, neurotoxicity, Wnt1, Wnt5a

\section{Introduction}

Parkinson's disease (PD) is a neurodegenerative disorder with high incidence among the elderly $(1,2)$. Symptoms of PD include motor defects and other non-motor disabilities. The main motor impairments are resting tremor, postural instability and bradykinesia. Non-motor disabilities include depression, anxiety, cognitive impairment and sleep disorders (3). One of the symptoms of PD is pathological selective degeneration of dopaminergic neurons (4).

Epidemiological studies demonstrated that exposure to pesticides increases the risk of PD (5). Paraquat (PQ) is an organic herbicide that can affect energy metabolism by inhibiting mitochondrial respiratory chain reactions (6). PQ can control certain intracellular signaling cascades (7). Maneb (MB) is a fungicide widely used in crop production that can influence dopamine (DA) homeostasis and mitochondrial function. It has been proposed that $P Q$, in the presence of $\mathrm{MB}$, alters the DA metabolism by enhancing the exposure of neurons to reactive oxygen species and reactive nitrogen clusters. A previous report, using rats as model organisms, demonstrated that combined exposure to $\mathrm{PQ}$ and $\mathrm{MB}$ is more toxic compared with exposure to PQ alone (8). MB can increase the content of $P Q$ in the brain by changing the metabolic dynamics of PQ and therefore converting non-toxic PQ into a toxic form (9)

PQ and MB are lethal pesticides frequently used in combination for crop production in China, including potatoes, tomatoes and other vegetables. Residual PQ and MB are frequently detected in China $(10,11)$.

The wingless (Wnt) protein family primarily includes secreted factors (12). Wnt1 and Wnt5a serve a role in the regulation of proliferation and differentiation of midbrain dopaminergic neurons (13). It has been demonstrated that Wnt1 and Wnt5a can interact to regulate the homeostasis of the nuclear receptor related factor 1 (Nurr1), and that Nurr1+ precursors promote formation of dopaminergic neurons in the midbrain $(14,15)$.

Previous research has indicated that exposure to environmental toxins can cause permanent damages to biochemical homeostasis and behavior of adult rats (16). The present study investigated the hypothesis that combined exposure to PQ and 
MB during the gestation and lactation period of rats can lead to alterations in Wnt1 and Wnt5a.

\section{Materials and methods}

Chemicals and reagents. PQ was purchased from $\mathrm{J} \& \mathrm{~K}$ Chemical Technology, Inc. (Beijing, China) and MB was purchased from Sigma-Aldrich (Merck KGaA, Darmstadt, Germany; both 98\% pure). Rabbit anti-Wnt1 (cat. no. ab85060; 1:1,000), anti-Nurr1 (cat. no. ab9332; 1:1,000), anti-Tyrosine hydroxylase (TH; cat. no. ab6221; 1:1,000) and anti-actin (cat. no. ab179467; 1:1,000) antibodies were purchased from Abcam (Cambridge, UK). An anti-Wnt5a antibody (cat. no. 55184-1-AP; 1:1,000) was purchased from Wuhan Sanying Biotechnology (Wuhan, China), and the goat anti-rabbit IgG antibody (cat. no. ZB-2305; 1:5,000) was purchased from Beijing Zhongshan Golden Bridge Biotechnology Co., Ltd. (Beijing, China).

Animals and treatments. The present study was approved by the Ethical Committee of the Harbin Medical University (Harbin, China). A total of 40 virgin female and 20 male Sprague-Dawley rats were purchased from Vital River Laboratories (Beijing, China). The animals were reared forl week in barrier facilities and then female and male rats were mated at 2:1 proportion. Vaginal smear was examined the next day and when sperm was identified, rats were categorized as day 0 subjects of the study. Pregnant rats were randomly divided into three groups: i) The saline treatment group, $1 \mathrm{mg} / \mathrm{kg}$ body weight saline, $(\mathrm{n}=10)$; ii) the high dose treatment group, $15 \mathrm{mg} / \mathrm{kg}$ body weight $\mathrm{PQ}+45 \mathrm{mg} / \mathrm{kg}$ body weight $\mathrm{MB}$, (n=15); and iii) the low dose treatment group, $10 \mathrm{mg} / \mathrm{kg}$ body weight $\mathrm{PQ}+30 \mathrm{mg} / \mathrm{kg}$ body weight $\mathrm{MB},(\mathrm{n}=15)$. Administration of saline, or $\mathrm{PQ}$ and $\mathrm{MB}$ was performed by gavaging twice a week from gestation to weaning. Rats were sacrificed following weaning.

Body weight and food consumption. Virgin female $(230 \pm 20 \mathrm{~g})$ and male Sprague-Dawley rats $(310 \pm 20 \mathrm{~g})$ used in the present study were 8 weeks old. The animals were provided water and food ad libitum. The animal cages were maintained at a constant $12 \mathrm{~h}$ light/dark cycle, temperature $22 \pm 2^{\circ} \mathrm{C}$ and relative humidity at $50 \pm 15 \%$. There was no significant difference in body weight and food consumption among females and offspring once a week during the experiment (data not shown).

High performance liquid chromatography with a fluorescence detector (HPLC-FL) determination of DA. The DA content was detected by HPLC-FL. The corpus striatum of the rats in each group were homogenized in $0.1 \mathrm{M}$ perchloric acid and centrifuged at $2,000 \mathrm{x}$ g for $20 \mathrm{~min}$ at $4^{\circ} \mathrm{C}$. The supernatant was then filtered through a $0.2 \mu \mathrm{m}$ cellulose membrane. The following chromatography conditions were used: $45 \times 150 \mathrm{~mm}$ VERIANODSCI8 column ( $5 \mu \mathrm{m}$; Nacalai Tesque, Inc., Kyoto, Japan); The mobile phase was composed of $20 \mathrm{mM}$ trisodium citrate and $50 \mathrm{mM}$ sodium hydrogen phosphate. The following chromatography conditions were used: Temperature, $35^{\circ} \mathrm{C}$; flow rate, $1.0 \mathrm{ml} / \mathrm{min}$. A fluorescence detector (Agilent Technologies, Inc., Santa Clara, CA, USA) was set at an excitation wavelength of $285 \mathrm{~nm}$ and an emission wavelength of $333 \mathrm{~nm}$. The data were quantified using the area under the peaks and external standards. The quantification was verified using calibration curves obtained from individual monoamine standards.

Total RNA extraction and reverse transcription-quantitative polymerase chain reaction $(R T-q P C R)$. The midbrain tissue was dissolved in TRIzol (Invitrogen; Thermo Fisher Scientific, Inc., Waltham, MA, USA) reagent. Total RNA was extracted from the treated midbrain tissue according to the manufacturer's protocol. Primers for rat Wnt1, Wnt5a, Nurr1 and TH were designed using the Primer Premier software (version, 5.0; Premier Biosoft Internetional, Palo Alto, CA, USA; Table I), based on Gene Bank sequences of these genes. Synthesis of cDNA was performed using PrimeScript RT reagent kit and gDNA Eraser (both from Takara Biotechnology Co., Ltd., Dalian, China), according to the manufacturer's protocol. qPCR reactions were performed using $\mathrm{SYBR}^{\circledR}$ Premix Ex $\mathrm{Taq}^{\mathrm{TM}}$ II kit (Takara Biotechnology Co., Ltd.) in $20 \mu \mathrm{l}$ reactions containing $2 \mu \mathrm{g}$ cDNA template and $10 \mu \mathrm{M}$ forward and reverse primers in an ABI 7500 Real-Time PCR system (Applied Biosystems; Thermo Fisher Scientific, Inc.). The following thermocycling conditions were used for the qPCR: Initial denaturation at $95^{\circ} \mathrm{C}$ for $30 \mathrm{sec} ; 35$ cycles of $94^{\circ} \mathrm{C}$ for $5 \mathrm{sec} ; 57.4^{\circ} \mathrm{C}$ for $20 \mathrm{sec}$ and $72^{\circ} \mathrm{C}$ for $20 \mathrm{sec}$; and final extension at $72^{\circ} \mathrm{C}$ for $1 \mathrm{~min}$. The threshold cycle was determined and the results are expressed as relative expression ratio. The relative expression ratio of a target gene was calculated as previously described (17).

Western blotting. Western blot analysis was used to quantify the protein amount of Wnt1, Wnt5a, Nurr1 and TH. Midbrain tissue was lysed in Radioimmunoprecipitation assay lysis buffer (Beyotime Institute of Biotechnology, Shanghai, China) for $2 \mathrm{~h}$ on ice. The protein concentrations in the supernatants were determined with a Bicinchoninic Acid protein assay kit (Beyotime Institute of Biotechnology). Protein samples, $4 \mu 1$ each protein per lane, were separated on $10 \%$ SDS-PAGE gels $(80 \mathrm{~V}, 20 \mathrm{~min})$. Proteins were electrophoretically transferred to polyvinylidene difluoride (PVDF) membranes. PVDF membranes were blocked in 5\% skimmed dry milk in Tris-buffered saline (TBS) at room temperature for $30 \mathrm{~min}$. Membranes were then incubated with primary antibodies at $4^{\circ} \mathrm{C}$ overnight. The following day, PVDF membranes were washed with TBS containing Tween-20 four times for 5, 10, 10 and 15 min. PVDF membranes were then incubated with a goat anti-rat horseradish peroxidase secondary antibody at room temperature for $60 \mathrm{~min}$. The PVDF membranes were then washed with TBS containing Tween-20 four times as previously. Antibody binding was detected using an enhanced chemiluminescence system (Tanon Science and Technology Co., Ltd., Shanghai, China). Density of the specific protein bands was standardized to $\beta$-actin with the Image $J$ software (version 1.5; National Institutes of Health, Bethesda, MD, USA).

Statistical analysis. Data are expressed as the mean \pm standard deviation. Data were analyzed using the SPSS software (version 17.0; SPSS, Inc., Chicago, IL, USA). The difference between groups was analyzed using analysis of one way analysis of variance and Bonferroni's multiple comparison was 
Table I. Primer sequences for the reverse transcription-quantitative polymerase chain reaction.

\begin{tabular}{lllcc}
\hline Target & \multicolumn{1}{c}{ Forward 5' $\rightarrow 3^{\prime}$} & \multicolumn{1}{c}{ Reverse 5' $\rightarrow 3^{\prime}$} & $\begin{array}{c}\text { Length } \\
(\mathrm{bp})\end{array}$ & $\begin{array}{c}\text { Annealing } \\
\text { temperature }\left({ }^{\circ} \mathrm{C}\right)\end{array}$ \\
\hline Wnt1 & TTTTCTCTCCGTGTCCCT & GCTCCCCAACCTTATTTC & 227 & 60 \\
Wnt5a & GACTTACCTCGGGACTGG & GACCTGCTTCATTGTTGTG & 166 & 58 \\
Nurr1 & CCAATCCGGCAATGACCAG & TGATGATCTCCATAGAGCCAGTCAG & 129 & 60 \\
TH & AGCTGTGCAGCCCTACCAAGA & GTGTGTACGGGTCAAACTTCACAGA & 140 & 62 \\
$\beta$-actin & GGAAATCGTGCGTGACATTAAAG & CGGCAGTGGCCATCTCTT & 74 & 60 \\
\hline
\end{tabular}

Wnt, wingless; Nurr1, nuclear receptor related hormone 1; TH, tyrosine hydroxylase.

A

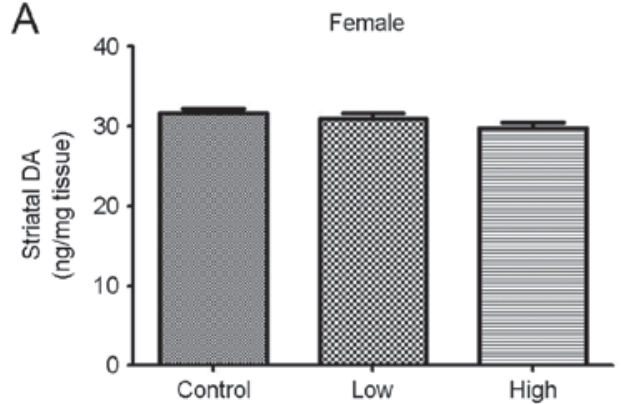

B

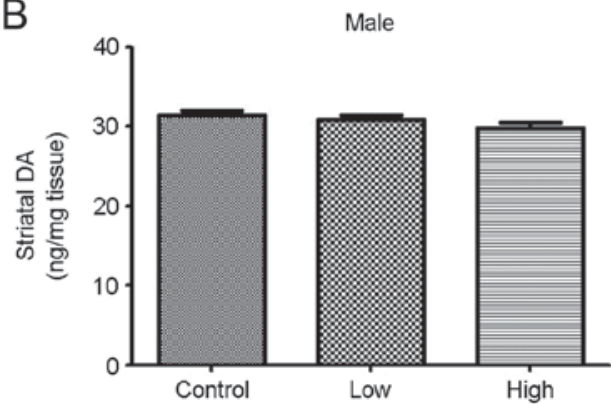

Figure 1. Effect of exposure to PQ and MB on striatal DA levels for (A) female and (B) male during gestation and lactation. Data are presented as the mean \pm standard deviation. $\mathrm{PQ}$, paraquat; $\mathrm{MB}$, maneb; DA, dopamine.

used as a post hoc test. $\mathrm{P}<0.05$ was considered to indicate a statistically significant difference.

\section{Results}

Effect of combined exposure to $P Q$ and $M B$ during development on DA levels. DA levels were measured following combined exposure to PQ and MB during gestation and lactation periods. The DA levels decreased upon exposure to PQ and $\mathrm{MB}$, but the differences were not statistically significant (Fig. 1).

Effects of combined exposure to $P Q$ and $M B$ during development on Wntl mRNA and protein expression levels. The effects of combined exposure to PQ and MB during development on midbrain Wnt1 protein and mRNA expression levels were studied in female and male offspring. mRNA and protein expression levels of Wnt1 decreased significantly upon combined exposure to PQ and MB at both high and low doses, compared with the unexposed control group. Among female offspring, mRNA expression levels decreased by 77.40 and $81.02 \%$, and protein expression levels decreased by 21.69 and $32.75 \%$ in the low and high dose groups, respectively. Among male offspring, mRNA expression levels decreased by 74.00 and $87.62 \%$, and protein expression levels decreased by 28.23 and $33.00 \%$ in the low and high dose groups, respectively (Fig. 2).

Effects of developmental exposure to $P Q$ and $M B$ on Wnt5a $m R N A$ and protein expression levels. The effect of combined exposure to PQ and MB during development on Wnt5a protein and mRNA expression levels in the midbrain, was investigated. mRNA and protein levels of Wnt5a were significantly increased following exposure to a high dose of PQ and MB, compared with the control group (all, $\mathrm{P}<0.05)$. Only protein expression of Wnt5a in both males and females was significantly increased upon exposure to low doses of $\mathrm{PQ}$ and $\mathrm{MB}$, compared with the control group $(\mathrm{P}<0.05)$. Among female offspring, mRNA expression levels increased by 18.94 and $86.68 \%$ and protein expression levels increased by 22.67 and $66.94 \%$, in the low and high dose groups, respectively. Among male offspring, mRNA expression levels increased by 30.61 and $117.03 \%$ and protein expression levels increased by 70.70 and $95.87 \%$, in the low and high dose groups, respectively (Fig. 3).

Effects of developmental exposure to $P Q$ and $M B$ on Nurrl mRNA and protein expression levels. As presented in Fig. 4, the effect of combined exposure to PQ and MB during development on midbrain Nurr1 protein and mRNA expression levels was studied in female and male offspring. mRNA and protein expression levels of Nurrl were significantly decreased following exposure to high doses of $\mathrm{PQ}$ and $\mathrm{MB}$, compared with the control group $(\mathrm{P}<0.05)$. Among female offspring, mRNA expression levels decreased by 32.29 and $49.84 \%$, and protein expression levels decreased by 12.93 and $23.90 \%$, in the low and high dose groups, respectively. Among male offspring, mRNA expression levels decreased by 55.57 and $62.50 \%$, and protein expression levels decreased by 16.55 and $28.47 \%$, in the low and high dose groups, respectively.

Effects of exposure to $P Q$ and $M B$ during development on TH MRNA and protein expression levels. The effects of 

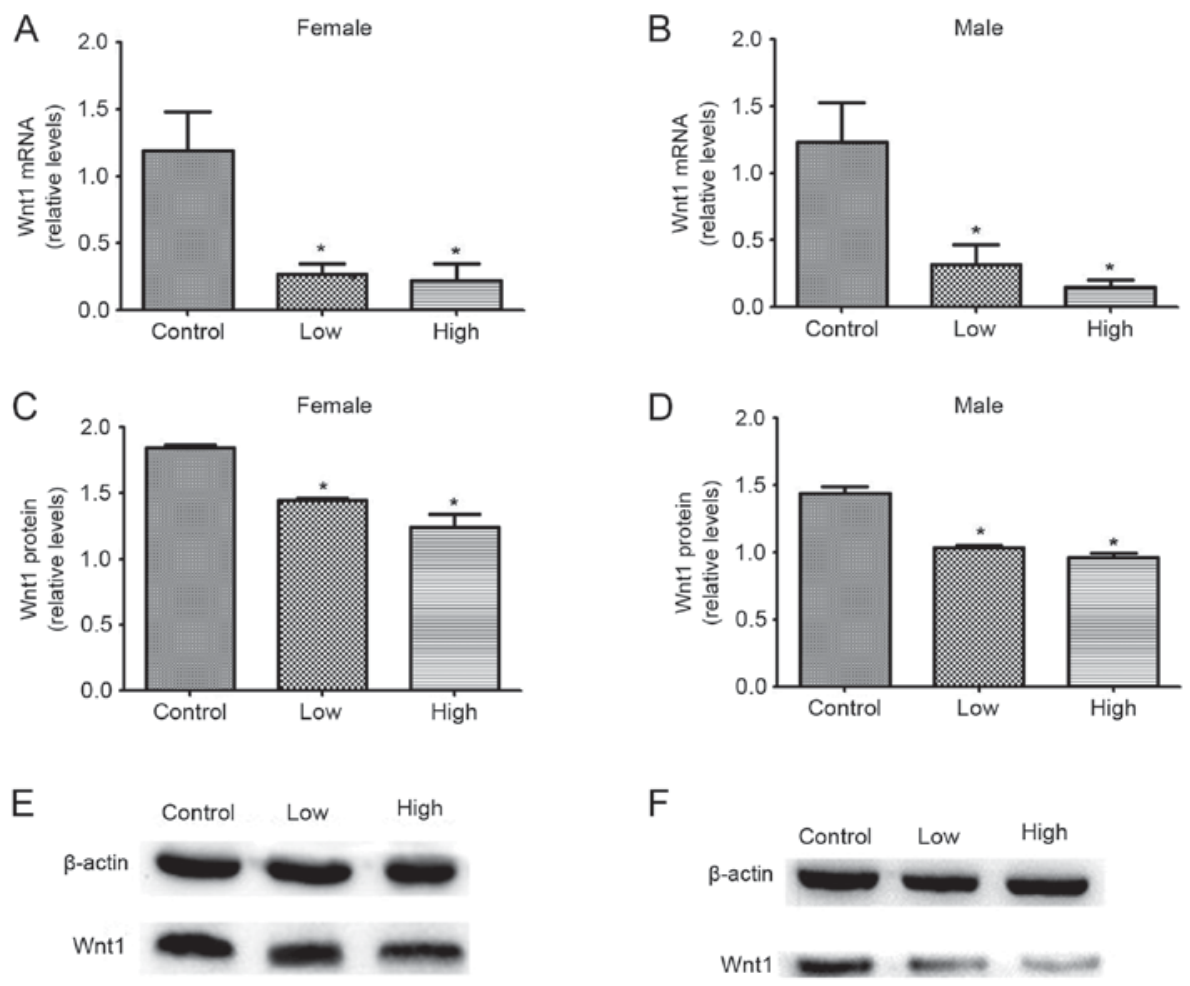

Figure 2. Wnt1 mRNA and protein expression levels in midbrain of offspring following combined exposure to PQ and MB during gestation and lactation. Alterations in Wnt1 mRNA levels in (A) female and (B) male offspring. Alterations in Wnt1 protein levels in (C) female and (D) male offspring. Western blot presenting relative expression of Wnt1 in (E) females and (F) males. Data are presented as the mean \pm standard deviation. ${ }^{*} \mathrm{P}<0.05$ vs. control. Wnt1, wingless; $\mathrm{PQ}$, paraquat; $\mathrm{MB}$, maneb; high, $15 \mathrm{mg} / \mathrm{kg}$ body weight $\mathrm{PQ}+45 \mathrm{mg} / \mathrm{kg}$ body weight $\mathrm{MB}$; low, $10 \mathrm{mg} / \mathrm{kg}$ body weight $\mathrm{PQ}+30 \mathrm{mg} / \mathrm{kg}$ body weight $\mathrm{MB}$.

A

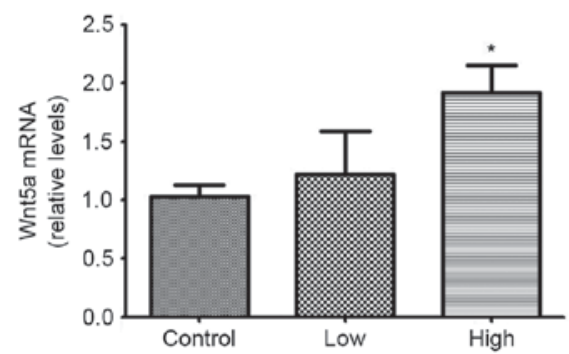

C

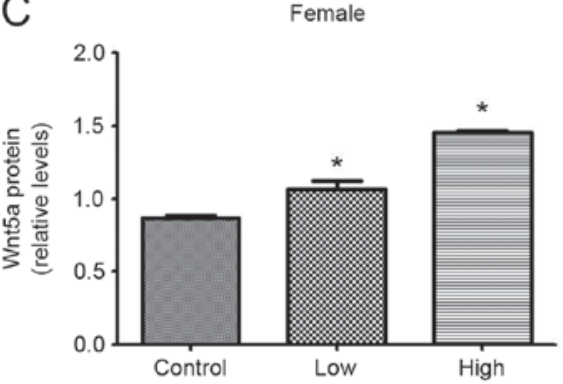

E

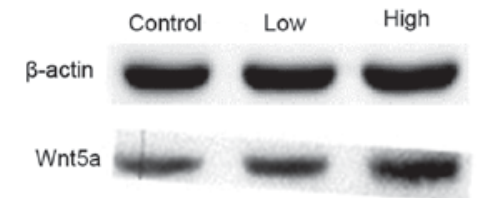

B

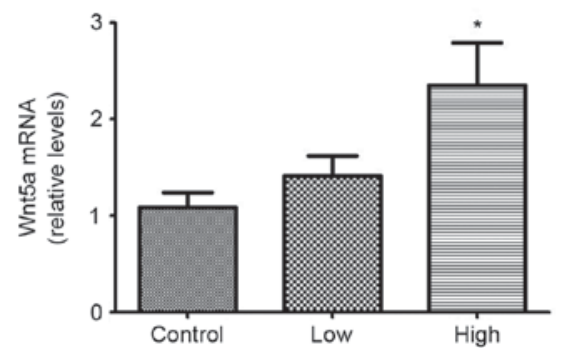

D Male

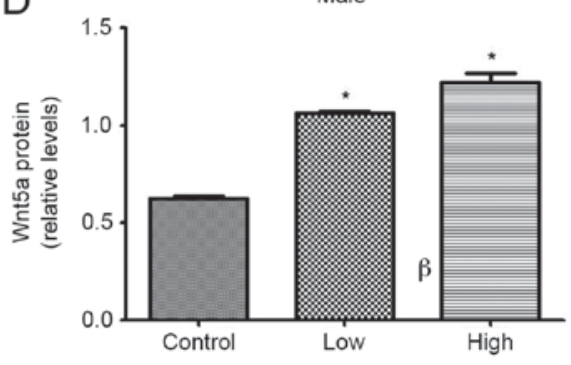

$\mathrm{F}$

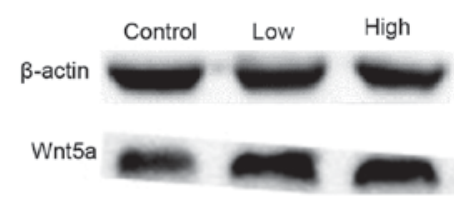

Figure 3. Wnt5A mRNA and protein expression levels in midbrain of offspring following combined exposure to PQ and MB during gestation and lactation. Alterations in Wnt5A mRNA levels in (A) female and (B) male offspring. Alterations in Wnt5A protein levels in (C) female and (D) male offspring. Western blot presenting relative expression of Wnt5A in (E) females and (F) males. Data are presented as the mean \pm standard deviation. ${ }^{\mathrm{P}}<0.05$ vs. control. Wnt $5 \mathrm{~A}$, wingless $5 \mathrm{~A} ; \mathrm{PQ}$, paraquat; $\mathrm{MB}$, maneb; high, $15 \mathrm{mg} / \mathrm{kg}$ body weight $\mathrm{PQ}+45 \mathrm{mg} / \mathrm{kg}$ body weight $\mathrm{MB}$; low, $10 \mathrm{mg} / \mathrm{kg}$ body weight $\mathrm{PQ}+30 \mathrm{mg} / \mathrm{kg}$ body weight $\mathrm{MB}$. 
A
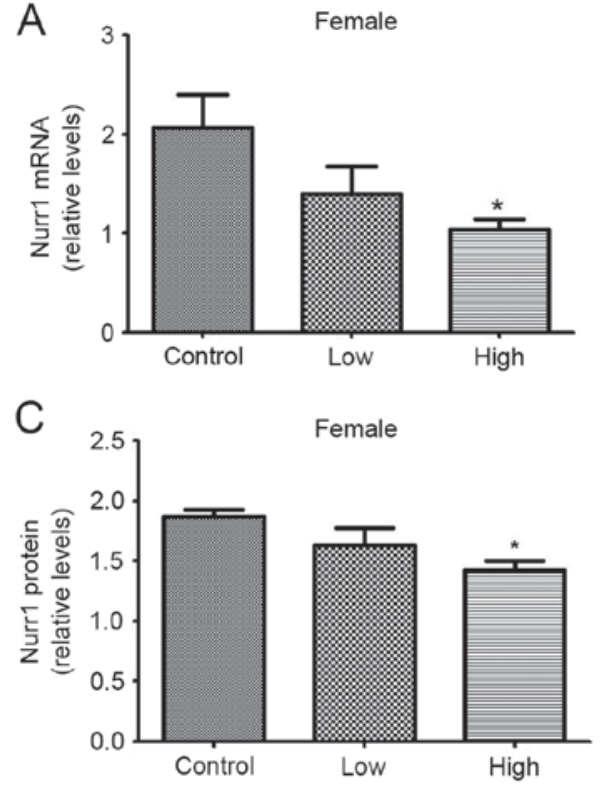

E

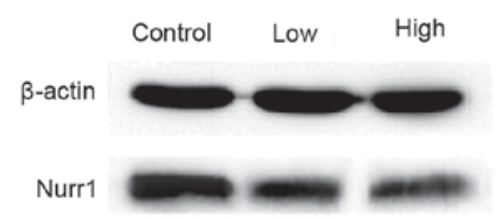

B

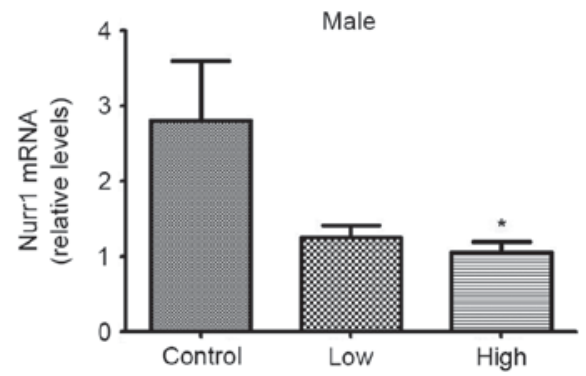

D

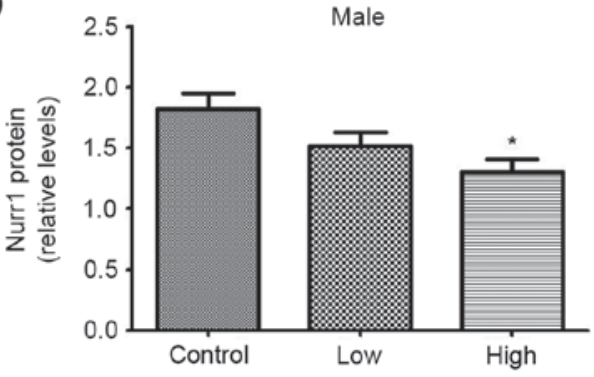

$\mathrm{F}$

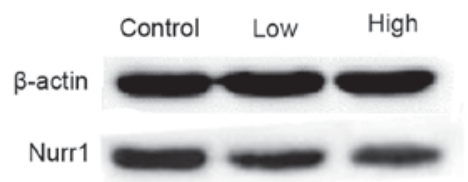

Figure 4. Nurr1 mRNA and protein expression levels in midbrain of offspring following combined exposure to PQ and MB during gestation and lactation. Alterations in Nurrl mRNA levels in (A) female and (B) male offspring. Alterations in Nurrl protein levels in (C) female and (D) male offspring. Western blot presenting relative expression of Nurrl in (E) females and (F) males. Data are presented as the mean \pm standard deviation. ${ }^{*} \mathrm{P}<0.05$ vs. control. Nurr1, nuclear receptor related hormone 1; PQ, paraquat; $\mathrm{MB}$, maneb; high, $15 \mathrm{mg} / \mathrm{kg}$ body weight $\mathrm{PQ}+45 \mathrm{mg} / \mathrm{kg}$ body weight $\mathrm{MB}$; low, $10 \mathrm{mg} / \mathrm{kg}$ body weight PQ $+30 \mathrm{mg} / \mathrm{kg}$ body weight MB.

combined exposure to PQ and MB during development on midbrain TH protein and mRNA expression levels in female and male offspring are summarized in Fig. 5. mRNA and protein expression levels of $\mathrm{TH}$ were significantly decreased following exposure to $\mathrm{PQ}$ and $\mathrm{MB}$ compared with the control group, but only when administrered at a high dose $(\mathrm{P}<0.05)$. Among female offspring, mRNA levels decreased by 19.90 and $52.43 \%$ and protein levels decreased by 13.68 and $28.79 \%$, in the low and high dose groups, respectively. Among male offspring, mRNA expression levels decreased by 14.21 and $48.14 \%$ and protein expression levels decreased by 7.86 and $33.35 \%$, in the low and high dose groups, respectively.

\section{Discussion}

PQ can cross the brain blood barrier directly as it has a similar structure to the toxic 1-methyl-4-phenylpyridinium $\left(\mathrm{MPP}^{+}\right)$, but the process is less efficient. $\mathrm{MPP}^{+}$can be bound by a transport protein of the dopaminergic neurons and transported to mitochondria. This process promotes excessive free oxygen radical secretion and induction of oxidative stress responses, which inhibit the activity of mitochondrial respiratory chain complex I and the synthesis of ATP, leading to denaturation and death of dopaminergic neurons (18). A number of studies investigated the effects of PQ on the Wnt signaling pathway. L'Episcopo et al (19) demonstrated that exposure to $\mathrm{MPP}^{+}$decreased protein expression of $\beta$-catenin and led to overexpression of phosphorylated glycogen synthase kinase $3 \beta$ in mice, affecting the Wnt signaling pathway. According to the results obtained by Gollamudi et al (20), combined treatment with PQ and MB affects Wnt pathways more significantly compared with the effect of PQ alone. MB selectively inhibits mitochondrial complex III which may lead to a reduction in DA release, and therefore an increase in DA concentration in synaptic vesicles (21). Therefore, combined treatment with MB and PQ can induce oxidative stress, and dopaminergic neurons can be more susceptible to injury caused by the oxidative stress (22). PQ can induce the injury of PC-12 cells in dopaminergic neurons through Wnt signaling pathways (23). Investigation of the combined effect of $\mathrm{PQ}$ and $\mathrm{MB}$ can have toxicological implications.

Previous studies have demonstrated that PQ and MB can permeate into embryos through the placental barrier during the early stage of brain development, affecting the development of dopaminergic neurons (24). Wnt1 and Wnt5a are secreted glycoproteins that serve a role on the formation and differentiation of midbrain dopaminergic neurons (25). Wnt1 activates the Wnt signaling pathway to promote the formation of midbrain dopaminergic neurons (26). Knockdown of Wnt1 impairs proliferation of dopaminergic precursors and leads to the death of dopaminergic neurons in the midbrain (27). Wnt5a promotes differentiation of neural cells into dopaminergic precursors (28). The knockdown of Wnt5a leads to enhanced proliferation of progenitor cells (29). 

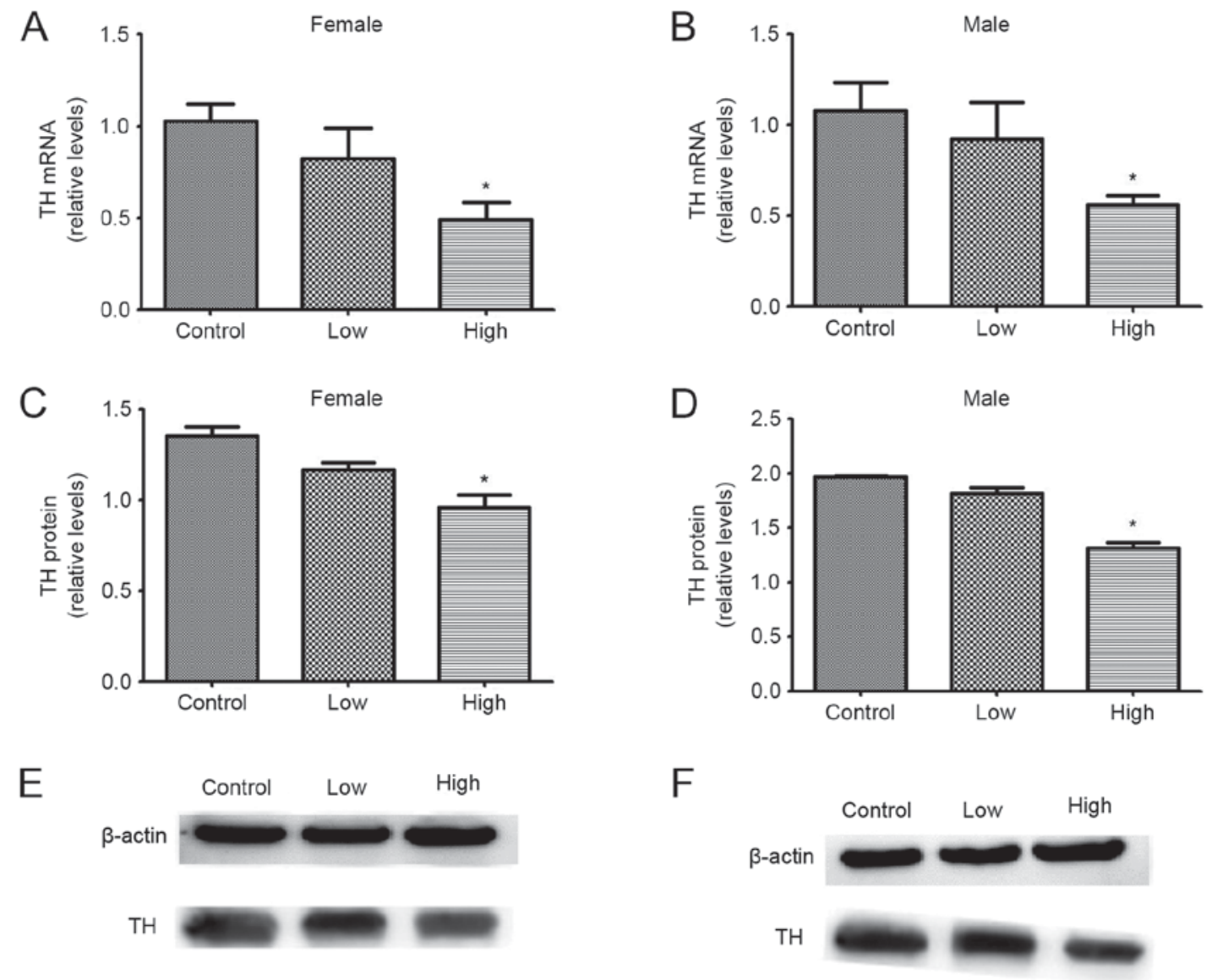

Figure 5. TH mRNA and protein expression levels in midbrain of offspring following combined exposure to $\mathrm{PQ}$ and $\mathrm{MB}$ during gestation and lactation. Alterations in TH mRNA levels in (A) female and (B) male offspring. Alterations in TH protein levels in (C) female and (D) male offspring. Western blot presenting relative expression of TH in (E) females and (F) males. Data are presented as the mean \pm standard deviation. " $\mathrm{P}<0.05$ vs. control. TH, tyrosine hydroxylase; PQ, paraquat; $\mathrm{MB}$, maneb; high, $15 \mathrm{mg} / \mathrm{kg}$ body weight $\mathrm{PQ}+45 \mathrm{mg} / \mathrm{kg}$ body weight $\mathrm{MB}$; low, $10 \mathrm{mg} / \mathrm{kg}$ body weight $\mathrm{PQ}+30 \mathrm{mg} / \mathrm{kg}$ body weight $\mathrm{MB}$.

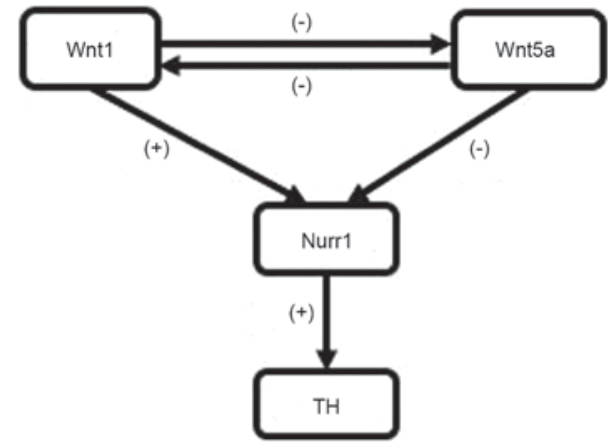

Figure 6. Effects of exposure to paraquat and maneb on Wnt proteins, Nurr1 and TH. Wnt, wingless; Nurrl, nuclear receptor related hormone 1; TH, tyrosine hydroxylase; (-), downregulated; (+), upregulated.

In the present study, pregnant rats were exposed to PQ and MB from the 5th day of gestation to weaning, a period during which Wnt proteins begin to be expressed (30). In the present study, it has been observed that exposure to PQ and MB during gestation and lactation leads to reduced and increased expression of Wnt1 and Wnt5a mRNA and protein expression, respectively, in both female and male offspring. Wnt1 and Wnt5a coordinate to promote the formation and proliferation of midbrain dopaminergic precursors (31).
Nurrl is expressed in the central nervous system and promotes the differentiation of neural precursors into dopaminergic neurons (32-34). Nurrl expression begins at day 10 of embryo development, reaches peak 1-2 days following birth, and then gradually decreases, but its expression remains high in the midbrain (35). Knock out of Nurrl during embryonic development can result in incomplete development of dopaminergic neurons (36). In the present study, exposure to PQ and MB during gestation and lactation led to reduced expression of Nurrl mRNA and protein expression, in both female and male offspring.

Previous studies have demonstrated that Nurrl directly regulates the promoter of TH gene (37). Upon activation, Nurr1 translocates to the nucleus, where it binds to the promoter region and activates the transcription of $\mathrm{TH}$ (38). TH is a marker for dopaminergic neurons and a rate limiting enzyme in the synthesis of dopamine (39-41). TH is only expressed in mature dopaminergic neurons, when enzymes and transporters specific for dopaminergic neurons are fully expressed and functional. Combined exposure to PQ and MB during gestation and lactation reduced TH mRNA and protein expression in both female and male offspring.

The effects of combined exposure to PQ and MB on DA levels in the striatum of offspring were investigated in the present study. DA levels in the striatum of offspring were not significantly decreased, even though $\mathrm{TH}$ expression was 
downregulated. It has been previously hypothesized that in order to maintain homeostasis, the synthesis, release, degradation and re-uptake of DA are regulated by multiple mechanisms (42). A plausible explanation of the results of the present study is that the transportation and re-uptake of DA were altered in order to compensate for the lack of DA synthesis and to maintain the function of the DA system. In theory, it is possible that the DA content in the striatum decreases with age and this decrease can cause symptoms of PD.

In conclusion, the present study demonstrated that combined exposure to PQ and MB during gestation and lactation alters the expression of proteins associated with the formation and development of dopaminergic neurons in offspring. It has been demonstrated that exposure to PQ and MB during gestation and lactation leads to upregulation of Wnt5a and down-regulation of Wnt1, Nurr1 and TH (Fig. 6). Future studies should investigate whether exposure to PQ and MB during gestation and lactation followed by a subsequent re-exposure during adulthood would enhance susceptibility of dopaminergic neurons to environmental risk factors.

\section{Acknowledgements}

The present study was supported by the National Natural Science Foundation of China (grant no. 81402711).

\section{References}

1. Hauser RA, Heritier S, Rowse GJ, Hewitt LA and Isaacson SH: Droxidopa and reduced falls in a trial of parkinson disease patients with neurogenic orthostatic hypotension. Clin Neuropharmacol 39: 220-226, 2016.

2. Goldman JG: Neuropsychiatric issues in Parkinson disease. Continuum 22: 1086-1103, 2016.

3. Savica R, Grossardt BR, Bower JH, Ahlskog JE and Rocca WA: Time trends in the incidence of parkinson disease. JAMA Neurol 73: 981-989, 2016.

4. Pathak K and Akhtar N: Nose to brain delivery of nanoformulations for neurotherapeutics in parkinson's disease: Defining the preclinical, clinical and toxicity issues. Curr Drug Deliv, 2016.

5. Ritz B and Yu F: Parkinson's disease mortality and pesticide exposure in California 1984-1994. Int J Epidemiol 29: 323-329, 2000.

6. Shimizu K, Matsubara K, Ohtaki K and Shiono H: Paraquat leads to dopaminergic neural vulnerability in organotypic midbrain culture. Neurosci Res 46: 523-532, 2003.

7. Finkbeiner S, Tavazoie SF, Maloratsky A, Jacobs KM, Harris KM and Greenberg ME: CREB: A major mediator of neuronal neurotrophin responses. Neuron 19: 1031-1047, 1997.

8. Thiruchelvam M, Prokopenko O, Cory-Slechta DA, Buckley B and Mirochnitchenko O: Overexpression of superoxide dismutase or glutathione peroxidase protects against the paraquat + maneb-induced Parkinson disease phenotype. J Biol Chem 280: 22530-22539, 2005.

9. Prakash J, Yadav SK, Chouhan S and Singh SP: Neuroprotective role of Withania somnifera root extract in maneb-paraquat induced mouse model of parkinsonism. Neurochem Res 38: 972-980, 2013

10. Kumari R, Jha RR, Singh MP and Patel DK: Whirling agitated single drop microextraction technique for the simultaneous analysis of paraquat and maneb in tissue samples of treated mice. J Sep Sci 39: 1725-1733, 2016.

11. Caputi FF, Carretta D, Lattanzio F, Palmisano M, Candeletti S and Romualdi P: Proteasome subunit and opioid receptor gene expression down-regulation induced by paraquat and maneb in human neuroblastoma SH-SY5Y cells. Environ Toxicol Pharmacol 40: 895-900, 2015

12. Ni W, Zeng S, Li W, Chen Y, Zhang S, Tang M, Sun S, Chai R and $\mathrm{Li} \mathrm{H}$ : Wnt activation followed by Notch inhibition promotes mitotic hair cell regeneration in the postnatal mouse cochlea. Oncotarget 7: 66754-66768, 2016
13. Kriks S, Shim JW, Piao J, Ganat YM, Wakeman DR, Xie Z, Carrillo-Reid L, Auyeung G, Antonacci C, Buch A, et al: Dopamine neurons derived from human ES cells efficiently engraft in animal models of Parkinson's disease. Nature 480: $547-551,2011$.

14. Alavian KN, Jeddi S, Naghipour SI, Nabili P, Licznerski P and Tierney TS. The lifelong maintenance of mesencephalic dopaminergic neurons by Nurr1 and engrailed. J Biomed Sci 21: 27, 2014.

15. Kitagawa H, Ray WJ, Glantschnig H, Nantermet PV, Yu Y, Leu CT, Harada S, Kato S and Freedman LP: A regulatory circuit mediating convergence between Nurr1 transcriptional regulation and Wnt signaling. Mol Cell Biol 27: 7486-7496, 2007.

16. Lee PC, Bordelon Y, Bronstein J and Ritz B: Traumatic brain injury, paraquat exposure and their relationship to Parkinson disease. Neurology 79: 2061-2066, 2012.

17. Yuan JS, Reed A, Chen F and Stewart CN Jr: Statistical analysis of real-time PCR data. BMC Bioinformatics 7: 85, 2006.

18. Schober A: Classic toxin-induced animal models of Parkinson's disease: 6-OHDA and MPTP. Cell Tissue Res 318: 215-224, 2004.

19. L'Episcopo F, Tirolo C, Testa N, Caniglia S, Morale MC, Deleidi M, Serapide MF, Pluchino S and Marchetti B: Plasticity of subventricular zone neuroprogenitors in MPTP (1-methyl-4phenyl-1,2,3,6-tetrahydropyridine) mouse model of Parkinson's disease involves cross talk between inflammatory and Wnt $/ \beta$-catenin signaling pathways: Functional consequences for neuroprotection and repair. J Neurosci 32: 2062-2085, 2012.

20. Gollamudi S, Johri A, Calingasan NY, Yang L, Elemento O and Beal MF: Concordant signaling pathways produced by pesticide exposure in mice correspond to pathways identified in human Parkinson's disease. PloS One 7: e36191, 2012.

21. Desplats P,Patel P, Kosberg K, Mante M,Patrick C, Rockenstein E, Fujita M, Hashimoto M and Masliah E: Combined exposure to Maneb and Paraquat alters transcriptional regulation of neurogenesis-related genes in mice models of Parkinson's disease. Mol Neurodegener 7: 49, 2012.

22. Barlow BK, Thiruchelvam MJ, Bennice L, Cory-Slechta DA, Ballatori N and Richfield EK: Increased synaptosomal dopamine content and brain concentration of paraquat produced by selective dithiocarbamates. J Neurochem 85: 1075-1086, 2003.

23. Yan M, Wang X, Zhao L, Chang X and Zhou Z: The effect of Wnt signaling pathway on paraquat induced $\mathrm{PC} 12$ cells damage. Zhonghua Lao Dong Wei Sheng Zhi Ye Bing Za Zhi 33: 806-811, 2015 (In Chinese).

24. Kumar A, Leinisch F, Kadiiska MB, Corbett J and Mason RP: Formation and implications of alpha-synuclein radical in maneband paraquat-induced models of Parkinson's disease. Mol Neurobiol 53: 2983-2994, 2016

25. Sousa KM, Villaescusa JC, Cajanek L, Ondr JK, Castelo-Branco G, Hofstra W, Bryja V, Palmberg C, Bergman T, Wainwright $\mathrm{B}$, et al: Wnt2 regulates progenitor proliferation in the developing ventral midbrain. J Biol Chem 285: 7246-7253, 2010.

26. Zhang J, Götz S, Vogt Weisenhorn DM, Simeone A, Wurst W and Prakash N: A WNT1-regulated developmental gene cascade prevents dopaminergic neurodegeneration in adult En1(+/-) mice. Neurobiol Dis 82: 32-45, 2015.

27. Barlow BK, Lee DW, Cory-Slechta DA and Opanashuk LA: Modulation of antioxidant defense systems by the environmental pesticide maneb in dopaminergic cells. Neurotoxicology 26: 63-75, 2005.

28. Andersson ER, Prakash N, Cajanek L, Minina E, Bryja V, Bryjova L, Yamaguchi TP, Hall AC, Wurst W and Arenas E: Wnt5a regulates ventral midbrain morphogenesis and the development of A9-A10 dopaminergic cells in vivo. PloS One 3: e3517, 2008.

29. Andersson ER, Saltó C, Villaescusa JC, Cajanek L, Yang S, Bryjova L, Nagy II, Vainio SJ, Ramirez C, Bryja V and Arenas E: Wnt5a cooperates with canonical Wnts to generate midbrain dopaminergic neurons in vivo and in stem cells. Proc Natl Acad Sci U S A 110: E602-E610, 2013.

30. Fischer T, Guimera J, Wurst W and Prakash N: Distinct but redundant expression of the Frizzled Wnt receptor genes at signaling centers of the developing mouse brain. Neuroscience 147: 693-711, 2007.

31. Gao H, Sun B, Fu H, Chi X, Wang F, Qi X, Hu J and Shao S: PDIA6 promotes the proliferation of HeLa cells through activating the $\mathrm{Wnt} / \beta$-catenin signaling pathway. Oncotarget 7 : 53289-53298, 2016. 
32. Zetterstrom RH, Solomin L, Jansson L, Hoffer BJ, Olson L and Perlmann T: Dopamine neuron agenesis in Nurr1-deficient mice. Science 276: 248-250, 1997.

33. Saucedo-Cardenas O, Quintana-Hau JD, Le WD, SmidtMP, Cox JJ, De Mayo F, Burbach JP and Conneely OM: Nurr1 is essential for the induction of the dopaminergic phenotype and the survival of ventral mesencephalic late dopaminergic precursor neurons. Proc Natl Acad Sci USA 95: 4013-4018, 1998.

34. Castillo SO, Baffi JS, Palkovits M, Goldstein DS, Kopin IJ, Witta J, Magnuson MA and Nikodem VM: Dopamine biosynthesis is selectively abolished in substantia nigra/ventral tegmental area but not in hypothalamic neurons in mice with targeted disruption of the Nurrl gene. Mol Cell Neurosci 11: 36-46, 1998.

35. Xiao Q, Castillo SO and Nikodem VM: Distribution of messenger RNAs for the orphan nuclear receptors Nurrl and Nur77 (NGFI-B) in adult rat brain using in situ hybridization. Neuroscience 75: 221-230, 1996.

36. Hermanson E, Joseph B, Castro D, Lindqvist E, Aarnisalo P, Wallén A, Benoit G, Hengerer B, Olson L and Perlmann T: Nurrl regulates dopamine synthesis and storage in MN9D dopamine cells. Exp Cell Res 288: 324-34, 2003.

37. Ding Y, Zhang Z, Ma J, Xia H, Wang Y, Liu Y, Ma Q, Sun T and Liu J: Directed differentiation of postnatal hippocampal neural stem cells generates nuclear receptor related1 protein and tyrosine hydroxylaseexpressing cells. Mol Med Rep 14: 1993-1999, 2016.
38. Kim KS, Kim CH, Hwang DY, Seo H, Chung S, Hong SJ, Lim JK, Anderson T and Isacson O: Orphan nuclear receptor Nurrl directly transactivates the promoter activity of the tyrosine hydroxylase gene in a cell-specific manner. J Neurochem 85: 622-634, 2003

39. Huang L, Deng M, He Y, Lu S, Liu S and Fang Y: $\beta$-asarone increases MEF2D and TH levels and reduces $\alpha$-synuclein level in 6-OHDA-induced rats via regulating the HSP70/MAPK/MEF2D/ Beclin-1 pathway: Chaperone-mediated autophagy activation, macroautophagy inhibition and HSP70 up-expression. Behav Brain Res 313: 370-379, 2016.

40. Medeiros HH, Santana MA, Leite MD, Aquino LA, de Barros MA, Galvão NT, Ladd FV, Cavalcante JC, Costa MS Cavalcante JS and Nascimento ES Jr: The cytoarchitectonic and TH-immunohistochemical characterization of the dopamine cell groups in the substantia nigra, ventral tegmental area and retrorubral field in a bat (Artibeus planirostris). Neurosci Res 112: 37-46, 2016.

41. Nagatsu T and Nagatsu I: Tyrosine hydroxylase (TH), its cofactor tetrahydrobiopterin $(\mathrm{BH} 4)$, other catecholamine-related enzymes and their human genes in relation to the drug and gene therapies of Parkinson's disease (PD): Historical overview and future prospects. J Neural Transm (Vienna) 123: 1255-1278, 2016.

42. Yu J, Li X, Yang J, Wu Y and Li B: Effects of simazine exposure on neuronal development-related factors in mn9d cells. Med Sci Monit 22: 2831-2838, 2016. 